\title{
Quem quer ser Raskólnikov? - o Theatrum Mundi em Antes do Degelo
}

\author{
Ivan Takashi Kano \\ (Universidade Federal Fluminense)
}

\section{RESUMO}

Este ensaio aborda o romance Antes do degelo, de Agustina Bessa-Luís, a partir de um traço da cultura do Barroco que parece permanecer na prosa portuguesa contemporânea. A percepção do mundo como teatro possibilita problematizar as relações do homem com a realidade e, nesse contexto, com a linguagem. Desse modo, o explícito diálogo intertextual entre o romance português e o clássico russo Crime e castigo, de Fiódor Dostoiévski, serve de ponto de partida para nossa leitura, que busca enfatizar, além da tensão própria ao processo de retomada do referente literário, outros dois aspectos correlacionados: primeiro, a tensa relação entre o crime e a linguagem que supostamente o representa; segundo, o processo de "deturpação" por que passa a trajetória de Raskólnikov, nas mãos de Agustina, processo este que garante a atualização e a pertinência de suas reflexões em torno dos valores que organizam este tempo depois do degelo.

PALAVRAS-CHAVE: Barroco, Representação, Agustina Bessa-Luís, Fiódor Dostoiévski, Romance português contemporâneo.

\begin{abstract}
This essay addresses Agustina Bessa-Luís's novel Antes do degelo departing from a trait of Baroque culture that seems to persist in contemporary Portuguese prose. The perception of the world as a theater allows one to problematize man's relation to reality, and, in that context, language. Thus, an explicit intertextual dialog between this Portuguese novel and Fyodor Dostoyevsky's Crime and Punishment functions as the starting point of our reading, which seeks to emphasize, beyond the tension that is proper to the process of resuming the literary referent, two other correlated aspects: first, the tense relationship between crime and the language that supposedly represents it; second, the process of "disfiguration" that Raskolnikov undergoes in the hands of Agustina, one which guarantees the update and pertinence of her reflexions about the values that organize this postdefrosting time.
\end{abstract}

KEYWORDS: Baroque, Representation, Agustina Bessa-Luís, Fyodor Dostoyevsky, contemporary Portuguese novel. 
"Há que fazer voltar à massa primitiva esta imundície. E que na torpitude de existir-se, ao menos possa haver as alegrias ingénuas de todo o recomeço." Jorge de Sena, "Tentações do Apocalipse"

"A maior parte das coisas belas fazem-se por imitação." Agustina Bessa-Luís, Antes do degelo

O aforismo cunhado por Agustina Bessa-Luís parece inevitavelmente atravessado pelo postulado que dá corpo ao pensamento de Aristóteles acerca dos caracteres da representação artística. Para o filósofo grego, na origem das poesias épica e trágica permanece a mesma predileção humana por conhecer e imitar a natureza, estabelecendo como fonte primária do prazer propiciado pela arte a possibilidade de, através dela, "aprender e identificar cada original", poder dizer, em suma, “"esse é Fulano”" (ARISTÓTELES, 1997, p. 22). Se Aristóteles, em nenhum momento, confunde o estatuto da arte com o da realidade, é inegável que entre ambos se estabeleça um vínculo direto, que funciona como princípio para a manifestação do belo. Antes do degelo, publicado pela autora portuguesa em 2004, parece retomar o paradigma clássico para, através de uma encenação intrincada de Crime e castigo, o romance emblemático de Fiódor Dostoiévski, instituir, quase como ironia, a impossibilidade de se restabelecer a segurança do elo entre arte e natureza. Seguindo os passos dos protagonistas do romance contemporâneo, parece que estamos diante de um texto que de fato nos permite dizer metonimicamente, e a todo momento, "eis Raskólnikov!". Mas os impasses começam a ganhar consistência no momento em que a literatura afirma sua autonomia com relação ao mundo, indo buscar em seus próprios depósitos os materiais necessários à sua permanência e vitalidade.

Representação da representação, Antes do degelo expõe os mecanismos da armadilha em que o romance se constitui. Pelas mãos de Agustina, o primeiro modo de compreender a apropriação do texto de Dostoiévski parece ser mesmo a função teatral que Crime e castigo exerce dentro da narrativa, não apenas no jogo de espelhos entre os dois romances, como veremos adiante, mas também, em um primeiro momento, na relação que os protagonistas mantêm com a história de Raskólnikov, o estudante pobre que assassina a velha agiota. Os atos de leitura demarcam a experiência dos personagens e servem, em certo sentido, como paradigma de imitação, texto teatral a partir do qual o mundo representado pela escrita de Dostoiévski revela-se como chave de um aprendizado, forma de apreensão do mundo que imediatamente os cerca:

Genaro achava o seguinte: que antes do degelo as tribos se juntavam dentro das cavernas e sonhavam com caçadas, ao mesmo tempo que afinavam as artes para tornar a vida melhor. Inventavam a roda e a agulha, poliam as armas, mastigavam as peles dos animais para as tornar maleáveis. Talvez aprendessem a falar enquanto a neve caía e a natureza estivesse em silêncio. Antes do degelo o homem avançou em seus três fascinantes factores de energia: a memória, a ansiedade e o afecto. 
Amou os filhos e as mulheres porque a convivência os tornou evidentes e activos na sua mente. $\mathrm{O}$ polegar correspondeu às informações do córtex cerebral. E por aí fora. Genaro dizia que o tempo do degelo estava no auge, não se mostrava nada preocupado com o crime urbano nem com a desordem mental da sociedade. $\mathrm{O}$ personagem mítico de José Rui era Raskolnikov, o estudante que assassina a velha agiota. Lia o livro vezes sem fim e encontrava sempre novas ideias. Quem era a velha agiota? Fumava um charro e punha-se a pensar. De certo modo, a miséria fazia-lhe falta, ou um ódio qualquer para acariciar. Vivia bem, tinha carro e um blusão de cabedal de marca. Se fosse Raskolnikov o que faria?" (BESSA-LUÍS, 2004, p. 32-33)

Ao investir na especulação filosófica, a escrita parece mais a serviço de reflexões diversas que orbitam ao redor da peculiar idealização do mundo por parte de Genaro. Daí que, no plano de seu enredo rarefeito, o romance se ocupe de narrar justamente este tempo depois do degelo, de aparentemente irrefreável liquefação dos valores que garantiriam a solidez da comunidade, construída pela harmonia entre os homens, e firmada no compromisso com uma "vida melhor". Envolvido nessa reflexão aparece o universo da literatura: da galeria de nomes convocados para tentar compreender/conter o degelo nos limites do texto somam-se a Dostoiévski autores como Kafka e Homero, para citar apenas alguns - desta galeria, como dizíamos, emerge o potencial da escrita como força motriz do processo de construção da realidade. É neste diálogo com a ficção que as mãos de Agustina deixam-se aparecer, a manipular os fantoches, quando, já ao final do texto, dá ao narrador a licença devida para assumir definitivamente o caráter ficcional do que acabamos de ler - "Os personagens deste livro são fictícios e qualquer semelhança com figuras reais não passa de mera coincidência." (BESSALUÍS, 2004, p. 365) -, e, do mesmo modo, assegurar que a "deformação" de Crime e castigo, realidade primeira que serve de base para a escrita do romance que aqui abordamos, possa de fato sugerir uma forma de resistir ao avanço do degelar. "Deturpar é reagir." (BESSA-LUÍS, 2004, p. 247)

Mas, então, que resposta subjaz às ações de Raskólnikov? De que modo o assassinato da usurária pode representar um valor positivo, uma saída para a "época envergonhada em que viviam” (BESSA-LUÍS, 2004, p. 80), em que vivemos? Para testar hipóteses, ou antes, para reforçar a necessidade de reação, Antes do degelo se abre a uma primeira percepção do mundo como teatro, da engrenagem cênica que estrutura a vida em sociedade e converte personagens em atores. Atentemos à cena transcrita abaixo:

Não era assim tão cara uma pérola de inferior qualidade e ela deliciava-se com a felicidade da jovem que a encontrava. Parecia que tinha sido nomeada para miss Mundo ou coisa assim. Chorava e tapava a boca com a mão, como tinha aprendido que se fazia, era um gesto que traduzia emoção e que todos compreendiam. Assim como tirar o cabelo do rosto e passa-lo para trás da orelha queria dizer que se é uma rapariga simples e em quem se pode confiar." (BESSA-LUÍS, 2004, p. 79) 
Cada ator conhece bem o papel que desempenha para manter o jogo de cena, e o próprio narrador parece assinalar sua posição de espectador, tradutor de gestos, em um afastamento do ponto de vista que lhe serve para revelar criticamente o vazio das práticas sociais.

A problematização do conceito de theatrum mundi - expressão tomada de empréstimo das reflexões do historiador José Antonio Maravall - requer, no entanto, algum esclarecimento, não só para evitar maiores imprecisões, como também para tentar manter a produtividade da ideia que sustenta esta análise. Temática destacada do período Barroco, a concepção do mundo como teatro é de fato um sintoma do grande impulso que a arte teatral tomou nesse período, mas adquire, na visão do historiador, implicações específicas. Ao sustentar estritamente este ponto de análise na leitura de peças como La vida es sueño, de Calderón de la Barca, Maravall se afasta de uma análise formal do teatro enquanto gênero ou espetáculo, para ressaltar aquilo que na teatralização está ligado, primeiro, ao "caráter transitório do papel designado a cada um, que somente se goza ou se sofre durante uma representação. Segundo, [a]o rodízio na distribuição de papéis, de maneira que o que hoje é um amanhã o será outro. [...]" (MARAVALL, 1997, 225), Nesse sentido, bem vistas as coisas, a manutenção desse tópico na arte do século XVII atua como mecanismo ideológico, aparelho regulador da ordem social vigente, na medida em que dirime a necessidade de modificar o status quo: durante o sonho de uma vida, a condição de senhor, vassalo, camponês, nobre - "todos sueñan lo que son" -, todos os papéis sociais, em suma, se igualam como mera transição, um mundo de aparências à espera do despertar para a realidade superior da existência humana, a vida do espírito.

Parece-nos claro, portanto, que no que se refere ao teatro social, Agustina Bessa-Luís assume outro posicionamento diante do mundo de aparências que se descreve, já que o aparente é, de maneira cabal, a própria essência do mundo em degelo: "Ninguém é o que parece. Era o que faltava! Se acertas com alguém que é o que parece ser, estás morto em pouco tempo.” (BESSA-LUÍS, 2004, p. 237)

Assim, o mesmo olhar que desnuda este teatro para criticá-lo vai propor outra espécie de encenação como mote para, talvez, investigar uma saída. Para tanto, o romance investe na construção de uma série de paralelismos com o enredo de Crime e castigo ${ }^{1}$ : do espelhamento entre os personagens de cada romance ao tempo da ação - "Nos princípios de Julho, com um tempo extraordinariamente caloroso, um jovem saía do seu cubículo que ocupava como sublocatário na travessa S***...” (BESSA-LUÍS, 2004, p. 38) -; passando pela presença misteriosa de um machado, objeto cênico fundamental, sob um amontoado de lenha até a descrição do cubículo onde vive Genaro, um decalque, com as devidas aspas, do quarto de Raskólnikov (BESSA-LUÍS, 2004, p. 45). Em suma,

Tudo era muito parecido com as cenas a que estavam acostumados, sobretudo Genaro, naquele prédio meio desmantelado. Também ali vivia uma viúva com filhos estudantes e havia uma linda rapariga que se sacrificava pela mãe e os irmãos, casando com um gordo negociante em vez de se casar com o rapaz que amava. (BESSALUÍS, 2004, p. 60)

Por outro lado, quando as similaridades querem firmar o pé do leitor no terreno de uma encenação orgânica, a escrita de Agustina Bessa-Luís parece submeter o discurso de Dostoiévski a um processo de deformação que, no trecho 
acima, aponta um sintoma interessante. É certo que não nos importa muito corrigir as pequenas confusões que Genaro faz entre os personagens do livro obsessivamente lido ${ }^{2}$, mas perceber que, ao ser presidida pela voz do narrador e pelos leitores que são José Rui e Genaro, a recuperação do texto russo se submete à memória. Nesse sentido, importa-nos assinalar, sim, o indício mais evidente de um recurso que atravessa o romance e que se faz imperativo na descontinuidade narrativa, no peso dado ao que ingenuamente constituiria simples divagações a preencher páginas. A ambiguidade, as lacunas deixadas por um discurso narrativo que recusa a dar vida ao que Omar Calabrese batizou de "monstro da totalidade" (CALABRESE, 1988, p. 101) dão corpo a uma escrita que investe sobre uma espécie de vazio inerente não mais à vida social, mas à própria condição do discurso verbal. Nada de que o leitor não tenha sido devidamente avisado pela direção de cena, antes de iniciar a peça:

Há pequenas impressões finas como um cabelo e que, uma vez desfeitas na nossa mente, não sabemos aonde elas nos podem levar. Hibernam, por assim dizer, nalgum circuito da memória e um dia saltam para fora, como se acabassem de ser recebidos. Só que, por efeito desse período de gestação profunda, alimentada ao calor do sangue e das aquisições da experiência temperada de cálcio e de ferro e de nitratos, elas aparecem já no estado adulto e prontas a procriar. Porque as memórias procriam como se fossem pessoas vivas. Acreditem que sim e passamos ao capítulo seguinte" (BESSA-LUÍS, 2004, p. 13)

O discurso da memória - como catalisador de uma escrita que desde logo expõe a lógica do seu próprio funcionamento - se constrói a partir de fragmentos cuja associação não serve à reconstituição de qualquer forma imperativa de realidade; e é assumindo tal impossibilidade que a memória, convertida em palavra, se mostra capaz de gerar algo novo. É justamente quando se afasta da mera encenação, quando desestabiliza o lugar confortável que o leitor encontrou no intertexto entre os romances, que Agustina atualiza a leitura de Crime e castigo. Para ser mais exato, é quando sua escrita tematiza o crime como algo que ultrapassa a questão social, para transformá-lo em um problema de linguagem.

Para tomar esse caminho de análise, creio ser interessante recortar pela primeira vez, aqui, um dos muitos e significativos diálogos do romance dostoivskiano. Em sua tentativa de desvendar a misteriosa morte da agiota, Razumíkhin ainda não sabe que o amigo Raskólnikov é o assassino, mas já reconstituiu o crime - ou imagina tê-lo feito - quando concatena uma narrativa muitas páginas antes que o juiz de instrução, por outros meios, viesse a solucionar o caso. Para o que nos importa, após a suposta descrição lógica dos fatos, cabe relembrar o final do diálogo entre Razumíkhin e Zóssimov. É este quem começa:

- Sutil! Não, meu caro, isso é sutil. Isso é o que há de mais sutil!

$-\mathrm{E}$ por que, por que isso?

- Ora, porque tudo saiu certo demais... e se encaixou... exatamente como no teatro. (DOSTOIÉVSKI, 2001, p. 155) 
No núcleo da pequena história criada pelo personagem subsiste a crença de que entre a linguagem e o mundo haja um espelho plano capaz de assegurar a ordem das coisas e, de certa maneira, garantir a precedência dessa ordem com relação à linguagem. Está claro que, longe de girar ao redor dos enigmas que alimentam a narrativa policial, Crime e castigo se ocupa de investigar, sim, as implicações do crime na ordem social e, mais que isto, a série de justificativas e contradições que movem o protagonista ao assassinato. Em termos restritos, o "teatro" concertado de um crime tem pouca ou nenhuma importância diante da hipótese filosófica que sustenta o fato de que Raskólnikov ceda a si mesmo o direito ao assassinato e o execute.

No jogo intertextual proposto por Agustina Bessa-Luís, o crime por si parece igualmente um detalhe. Se é possível relacionar esquematicamente os personagens José Rui, Genaro e Judite aos seus pretensos referentes - Raskólnikov, Razumíkhin e Dúnia, respectivamente -, no sétimo capítulo de Antes do degelo o suposto assassinato de Cláudia começa a embaralhar a distribuição dos papéis:

\section{Cláudia foi assassinada - disse José Rui.}

Não compreendia; mas também não fez nada para ficar mais esclarecido. Esperou ainda um pouco, porém o amigo não disse mais do que isso. Era uma novidade para ele, ou não seria uma novidade mas uma informação que ficava registada no conselho da família. Ninguém estava interessado em enredar o caso, não havia nenhum ganho em levar até à polícia e aos jornais a vida particular de Cláudia. Morria portanto de um aneurisma, como era natural que acontecesse a qualquer pessoa." (BESSALUÍS, 2004, p. 162)

Reduzido a uma afirmativa que não se desenvolve ou esclarece, o controverso assassinato serve apenas para que alguém assuma o papel da velha usurária, e, consequentemente, para deixar em suspenso a resposta mais importante: quem é o Raskólnikov dessa "nova versão"? Tal questão implica em refletir acerca de um problema prévio: importa a Agustina Bessa-Luís respondêla? Se sim, de que modo?

Uma hipótese possível seria desenvolver uma narrativa policial dentro do romance. Afinal, ao desenrolar do inquérito, coincidente com o avançar das páginas, encontraríamos seguramente, pelas mãos do narrador, o assassino, suas motivações, as circunstâncias do delito e talvez ainda assistíssemos, como prêmio, à punição do culpado. Seguindo tal hipótese, estaríamos diante daquilo que Jorge Luís Borges chamou, referindo-se ao conto policial, "género intelectual" por excelência (BORGES, s/d, p.69). Mais importante: demarcando um lugar de enunciação, Borges afirmará ainda que, embora em declínio em nosso tempo, o gênero policial tem o mérito de conservar as virtudes clássicas em uma época em que se tende "a suprimir personagens e argumentos; tudo é muito vago", época, afinal, "em que a literatura tende para o caótico" (BORGES, s/d, p. 74).

A quase melancólica defesa do conto policial, feita pelo escritor argentino, marca, sem dúvida, um contraponto com a escrita de Antes de degelo, já que, ao que parece, é justamente em direção ao caótico que o romance afirma suas tensões. O crime levanta uma série de suposições que servem de pretexto para o aparecimento do personagem Ricote, figura que apenas de forma caricatural ocuparia o papel do competente juiz de instrução Porfiri Pietróvich, criado por Dostoiévski, 
responsável por solucionar o caso. Mais uma vez, a manipulação dos móbiles da ficção está longe de mimetizar fielmente o livro - ou o que quer que se queira tomar como realidade anterior à escrita de Agustina. Se, em certa leitura do conto policial, pode-se dizer que o crime produг e precede uma linguagem, a imprecisão calculada do romance português turva o assassinato, deixa um sem-número de pegadas desencontradas diante das quais todos são suspeitos e mesmo a causa de morte de Cláudia é posta em dúvida. Daí que o inquérito perca a função, a solução, porque inútil, não é capaz de recuperar a ordem perdida. Por seu turno, a linguagem, que se nega a participar dessa espécie de triunfo do real, parece mais preocupada em representar o constante "regresso a si mesm[a], pôr em evidência do seu próprio reflexo, encenação da sua maquinaria” (SAUDUY, s/d, p. 54). Tais palavras de Severo Sarduy abrem caminho para compreender esta representação peculiar, uma forma de mimesis barroca no romance contemporâneo:

O lugar é sempre o lugar do crime. Um crime não explicado é motivo de inquietação. Estão rodeados, tais crimes, por uma nuvem de emoções quase sempre indescritíveis. É fácil que essas emoções atinjam, pouco a pouco, uma espécie de ambiguidade que manifesta a perturbação mental tanto dos indivíduos como da sociedade em geral. Quanto mais as pistas se confundem e as tendências inconscientes dos juízes e dos investigadores assumem proporções delirantes, mais o crime personifica o mal-estar da vida. Não se encontra saída para o enredo que cada vez mais se avoluma. A nossa concepção de realidade sofre um forte abalo" (BESSA-LUís, 2004, p. 225)

A impossibilidade de reconstituir o crime, à maneira de Razumíkhin, implica na impossibilidade de retomar o bem estar da vida, não mais aquele que corresponde à ordem social que se busca conservar na solução do caso, mas sobretudo aquele que reflete a manutenção e a continuidade do sentido da realidade, sentido que se deseja sempre liberto da ambiguidade. O que a linguagem em Antes do degelo trata de questionar, portanto - em mais uma encenação de si mesma -, é nossa concepção de real, ao inverter, de certa forma, as posições da relação, porque, à primeira vista, é a linguagem que produz o crime.

Mas, se é lícito dizer que a linguagem não representa o crime, mas o constrói, também não parece totalmente exato afirmar que esteja aí o cerne do problema, uma vez que a capacidade de representar o crime através da linguagem - no movimento que leva da infração da ordem ao inquérito, do inquérito à solução e desta à retomada posterior da ordem - implica em compactuar com a manutenção desse imperativo de realidade. Afastando-se definitivamente das formas de poder, o discurso literário de Agustina, pelo que estamos assinalando neste ensaio, faz recordar as reflexões de Roland Barthes quando, ainda no início da Aula que inauguraria a cadeira de Semiologia Literária no Colégio de França, acusava o fascismo inerente à língua, imbricado no caráter opressivo que ela exerce ao sujeitar os falantes a um número limitado de formas que ela nos obriga a utilizar. No conflito entre o poder que o uso da linguagem empresta ao sujeito - o primeiro deles, o de constituir-se sujeito - e a submissão deste aos imperativos daquela, o que ressalta, para Barthes, é a função libertadora da literatura como trapaça "que 
permite ouvir a língua fora do poder no esplendor de uma revolução permanente da linguagem" (BARTHES, 1980, p. 16).

O narrador avisa: "Nem que um livro tivesse mil páginas e uma só personagem, nada ficava apurado, conhecido, posto a nu" (BESSA-LUÍS, 2004, p. 337). Não à toa, traços da escrita como a proliferação de informações vagas, a descontinuidade temporal da narração; o gosto pelos parágrafos longos com constantes mudanças de tema, associados à recorrência de aforismos e à reiteração de frases - muitas delas em itálico; o peso dado à digressão muitas vezes em detrimento da efabulação - algumas características do trabalho da escritora portuguesa, em suma, parecem mesmo apontar para uma revolução fundada no rechaço ao pacto tradicional entre linguagem e realidade e na afirmação do caráter estético do que se está a produzir através do labor da escrita. A linguagem do romance, ao recusar-se a construir o crime, e tendo a sua própria desordem como programa revolucionário - se quisermos utilizar o tom barthesiano -, ensaia a subversão sobre si mesma. A linguagem comete o crime. Será por isso que, quando Raskólnikov "se valeu da confissão, não foi porque a culpa o apoquentasse, mas foi para matar a curiosidade dos outros. Foi para praticar o seu autêntico crime" (BESSA-LUÍS, 2004, p. 226, grifo da autora)?

As metáforas do teatro, que orientam esta leitura de Antes do degelo, não servem propriamente - e é bom que diga a tempo de desfazer mal-entendidos para alimentar um diálogo entre gêneros, do romance com o texto e a representação teatrais em sentido restrito. Em última análise, como é próprio da mimesis barroca, a linguagem encena a si mesma no sentido de que se coloca no primeiro plano para questionar seu papel coadjuvante de espelho do mundo. Na roda viva da literatura, o crime que a linguagem comete, ao afirmar sua autonomia, reforça, na verdade, o traço filosófico que une a escrita de Agustina à de Dostoiévski, uma grafia sobre a outra:

Portanto, vamos recapitular a morte da usurária: quem tinha motivos para matar; e quem não tinha motivos, o que é igualmente importante. Eu, Judite e Charo tínhamos motivos. Tu, o Medeiros, Vicenta, não tinham, mas podiam chegar lá por outras vias. E os desconhecidos? Resta decifrar os sinais dos desconhecidos, os amigos, convidados. Seria um crime por vingança ou por desejo de proveito? Ou um crime puramente arcaico, por impulso de remover uma coisa incómoda, como faz um selvagem ao abater um obstáculo? Tudo é plausível (BESSA-LUÍS, 2004, p. 349-350)

Quanto mais se desfaz qualquer expectativa de atribuir um assassino a Cláudia - definitivamente acomodada no papel que lhe foi designado -; quanto mais se afasta daquele tipo de leitor que Borges disse ter sido criado por Edgar Allan Poe (BORGES, s/d, p. 64); mais a narrativa parece reiterar o problema: em que sentido, afinal, o assassinato cometido pelo protagonista de Crime e castigo representa um valor a ser apreendido por nossos obcecados personagens leitores? Se admitimos que o romance sugira algum tipo de resposta, somos desde logo levados a assumir que não é sobre o criminoso em si que recaem as luzes de palco.

Trazida à tona pela leitura do romance de Dostoiévski, a questão do limite retorna de alguma forma em Antes do degelo, transfigurada na reflexão acerca da 
finitude humana, que, por sua vez, dá consistência ao que parece ser um dos eixos fundamentais do romance: a culpa como poder capaz de refrear o degelo. Assim, os protagonistas não só inocentam o estudante, alegando ser o crime uma consequência das circunstâncias em que vivia (BESSA-LUÍS, 2004, p. 96), como, aos poucos, parecem revestir o personagem de um caráter heroico. E, sob certos aspectos, acabam também por ressignificar sua história.

Para o Raskólnikov de Dostoiévski, seu crime está longe de ser produto de um impulso irrefletido, mas, ao contrário, representa o culminar de uma elaboração teórica. Exposta em um certo artigo "Sobre o crime", a razão do personagem oferece a chave não só para compreender a dimensão filosófica do ato, mas também para que, no plano policial, o juiz de instrução comece a solucionar o caso. Por sua vez, nos traços que Agustina parece querer destacar na face do estudante, expõe-se a razão por que, embora muitos dos atores possam ocupar o lugar de Raskólnikov em Antes do degelo, nenhum deles parece estar à altura do papel. Tal como Dostoiévski, Agustina indaga o caráter de seus personagens centrais. E, desse modo, em seu cerne, o raciocínio que justifica o assassinato cometido por Raskólnivkov vale igualmente para José Rui e seu duplo, Genaro:

É só na minha idéia central que eu acredito. Ela consiste precisamente em que os indivíduos, por lei da natureza, dividem-se geralmente em duas categorias: uma inferior (a dos ordinários), isto é, por assim dizer, o material que serve unicamente para criar seus semelhantes; e propriamente os indivíduos, ou seja, os dotados de dom ou talento para dizer em seu meio a palarra nova." (DOSTOIÉVSKI, 2001, p. 269)

Permanece a questão de saber se Raskólnikov, ao matar a velha agiota com as costas do machado, foi capaz de suplantar o limite que separa as duas categorias. O que Dostoiévski parece acentuar é justamente o fracasso desse intento. Depois de executar o plano, o estudante começa a se dar conta de que seu crime não representava um estágio necessário à instituição de um bem maior, mas que havia, na verdade, "matado um princípio" (DOSTOIÉVSKI, 2001, p. 284), já que, embora rompa com a lei antiga, não conseguira ultrapassar o limite, instaurar outra ordem. Na racionalização extrema de sua ação, Raskólnikov permanece aquém do seu ideal. É importante notar o fato de que o tal princípio faz com que ele não se veja como criminoso - espelhando-se em figuras inocentadas pela história, como Napoleão Bonaparte - para compreender o sofrimento que advém da percepção de si mesmo como um homem ordinário, desses que, como a maioria de nós, permanece "do lado de cá" (DOSTOIÉVSKI, 2001, p. 284). Pode-se mesmo afirmar que a maior parte de seu sofrimento provenha daí. Por outro lado, talvez seja possível afirmar também que, ao matar o princípio que o inocentava, o protagonista se veja finalmente como criminoso, e, nesta falha da sua predominante racionalidade, instala-se a culpa, acentuada pelo assassinato da irmã da velha e cuja expiação, ao que parece, terá termo somente através do amor por Sonia. E a culpa pelo crime acabaria por aprisionar o protagonista à condição de homem inferior.

Pois é da mesma fenda por que escapa a culpa de Raskólnikov que medra a reflexão no romance contemporâneo: 
As pessoas estão a tornar-se falhadas porque já não têm nada de que culpar-se. Nada tem importância. Se te masturbas ou violas uma criança, isso não é uma vergonha nem um pecado, é um erro. Mas o que é um erro? Sei o que é um erro quando as contas não dão certas, as contas de somar e de dividir. (BESSA-LUÍS, 2004, p. 87)

A percepção do mundo em degelo impõe a emergência de se redescobrir valores capazes de reconstruir os vínculos de responsabilidade mútua entre os homens, e, nesse sentido, a culpa se converte na energia capaz de estabelecer o reencontro do homem com sua natureza humana (VASCONCELOS, 2008). A profunda consciência da morte, como condição inerente à existência e, sobretudo, como força renovadora - a força capaz de transformar o Apocalipse em uma tentação, como nos lembra Jorge de Sena -, parece transformar o crime de Raskólnikov em uma forma de fazer o homem agir em favor de sua sobrevivência como ser, possibilitar o encontro com a alegria do recomeço, com aquele tempo Antes do degelo, pleno de energia criativa:

O mundo já não precisava de gente inteligente, só de gente eficaz. Os governos eram agora prestáveis, sentimentais e prontos a perdoar; não sabiam que o ponto nevrálgico da energia humana é a culpa; e Raskolnikov representa o grande inventor da culpa no sentido de lhe dar plenos poderes para o sofrimento, tesouro que os deuses reservam aos criadores. (BESSA-LUÍS, 2004, p. 308)

Sobretudo, salta da reflexão de Agustina a certeza de que a cada um de nós cabe matar sua velha usurária para garantir o sentido da existência ${ }^{5}$. Desse modo, o romance opera o desejo de Raskólnikov de figurar no rol dos homens extraordinários, daqueles - vale lembrar - capazes de "dizer em seu meio a palarra nov 'a", redefinindo o trajeto do personagem dostoievskiano. A referência do romance ao ensaio em que Freud reúne Hamlet, Édipo e os Irmãos Karamazor não só sinalizaria, aqui, a questão do parricídio, mas também reforça a da culpa, que faz com que os três textos ascendam do terreno policial à esfera da tragédia: “[o] enigma é trágico, a curiosidade é um traço policial destinado a cumprir com a lei como um factor urbano e não como um factor inconsciente" (BESSA-LUÍS, 2004, p. 284). Convertido em homem extraordinário pelas mãos de Agustina Bessa-Luís, Raskólnikov obtém licença para reescrever o significado de seu ato, não no seu sentido histórico, como um Napoleão, mas sem dúvida no sentido filosófico e, de certo modo, trágico. É para instituir a culpa como força criadora que ele age contra um status quo que está sempre aquém daquilo que o move, impulsionado pelo sentimento patético, "uma comoção espontânea sem necessidade de conscientização de sua origem ou finalidade." (STAIGER, 1975, p. 126, grifo nosso). A quem, como ele, vivencia a tensão dramática entre a consciência de se saber superior e a mesquinhez do mundo, e "chegou ao crime como se não houvesse caminhado pelas próprias pernas” (DOSTOIÉVSKI, 2001, p. 465), somente o sentido trágico é capaz de inocentar: 
Um sentimento pueril, como se fosse uma doença, apoderava-se dele e, no seu auge, o crime tornava-se inevitável. O homem só à custa de enorme sofrimento suporta a razão e, na quebra desse pacto com a razão, há como que um acordo com o ser primitivo, mais feliz, como se não houvesse motivo para ser castigado. A razão era um efeito da vontade e não havia crime no acto que tinha praticado (BESSA-LUÍS, 2004, p. 161)

Pelas mãos de Agustina Bessa-Luís, o caminho que vai da inevitabilidade do crime à inevitabilidade do destino como personagem ficcional lança Raskólnikov à dignidade de herói trágico; o sofrimento que o assola se firma definitivamente como o agente capaz de sinalizar o retorno ao ser primitivo, e, finalmente, ao tempo antes do degelo - como se vivenciar plenamente a culpa por um ato cujo sentido lhe foge à razão fosse a única forma de libertar-se. E é esta possibilidade de retorno que, em sentido último, o inocenta. A José Rui e Genaro - assim como para todos os outros atores envolvidos em Antes do degelo -, no entanto, cabe apenas assistir à peça de suas próprias vidas com a certeza melancólica de que nenhum deles será mesmo capaz de suplantar o limite da mesquinhez de suas aspirações, entre heranças, casamentos de fachada e outros pequenos vícios que mantêm em ordem o teatro do mundo ${ }^{6}$. Nenhum deles pode ser Raskólnikov e, em sua grandeza, empunhar um machado:

Que espécie de mística representava o machado debaixo da lenha? A mesma que levou Abraão ao Monte Mória e ali preparou o sacrifício do filho. À última hora apareceu uma ovelha, ou cabra, para substituir a criança. Mas a verdade é que se disse o mesmo de Agamêmnon quando teve que derramar o sangue da filha Ifigênia para que as naves pudessem ser levadas a Tróia pelo vento. $\mathrm{E}$ disseram que uma corça apareceu e foi ela a sacrificada. Uma série de embustes, porque tudo podia ser concertado entre os conhecedores dos ventos e dos mares e os estrategos. Não há grandeza nenhuma na vida. (BESSALUÍS, 2004, p. 201)

Em dissolução é, também, este tempo em que os modelos provindos da literatura, a despeito do esforço dos protagonistas do romance, já não passam de embuste, bens, como se nota, de valor questionável. Mas é com melancolia que se aceita o fato de que a vida não consiga mais imitar a arte e ter acesso ao belo. Para Agustina, a única forma de restabelecer a grandeza da vida é insistir no labor da escrita, já que não há como cumpri-lo sem fazê-la imitar infinitamente a si mesma no diálogo e ressignificação constante de suas fontes. "Reflectir é matar" (BESSALUÍS, 2004, p. 160), escrever, sua forma de empunhar o machado. Mas para seus personagens, talvez, a saída ainda não se tenha oferecido de forma tão clara. Aos homens ordinários resta somente seguir assistindo ao degelo, este sim, inevitável. 


\section{NOTAS}

1. Vale reforçar, aqui, como vimos apontando anteriormente, que são os próprios personagens, como leitores, que percebem as similaridades entre o que vivenciam e as passagens do romance de Dostoiévski.

2. Consta, por exemplo, que Dúnia, personagem de Dostoiévski, possivelmente a jovem referida que se sacrifica pela mãe e o irmão, venha a noivar com um negociante, mas nem se casa, e tampouco o faria em lugar de um rapaz que amasse.

3. A princípio mera coincidência, talvez destas "que provocam a realidade" (BESSA-LUÍS, 2004, p. 365) de Antes do degelo como objeto estético, é também no sétimo capítulo, mas da primeira parte de Crime e castigo que se desenvolve a cena do assassinato da velha usurária.

4. É o posicionamento de Paulo Bezerra no prefácio ao romance, praticamente excluindo a hipótese de que o crime desperte o sentimento de culpa por parte do protagonista, a não ser pelo assassinato da irmã da velha usurária.

5. Ou, de acordo com a leitura de viés benjaminiano de Viviane Vasconcelos, Antes do degelo assenta, em seu sentido alegórico, a certeza de "haver muitos motivos para se carregar um machado" (VASCONCELLOS, 2008).

6. Dentre as muitas descrições e recomendações de Aristóteles em sua Poética acerca do gênero, ressalte-se a afirmação de que "a tragédia [é] a representação de seres melhores do que nós (...)" (ARISTOTELES, 1997, p. 35).

\section{REFERÊNCIAS BIBLIOGRÁFICAS}

ARISTÓTELES. A poética clássica. Trad. Jaime Bruna. São Paulo: Cultrix, 1997. BARTHES, Roland. Aula. Trad. Leyla Perrone-Moisés. São Paulo: Cultrix, 1980. BESSA-LUÍS, Agustina. Antes do degelo. Lisboa: Guimarães Editores, 2004.

BORGES, Jorge Luís. O conto policial. In: Borges oral. Trad. Rafael Gomes Filipe. Lisboa: Vega, s/d, pp. 63-74.

CALABRESE, Omar. A idade neobarroca. Trad. Carmen de Carvalho e Artur Morão. Lisboa: Edições 70, 1988.

DOSTOIÉVSKI, Fiódor. Crime e castigo. Trad. e prefácio de Paulo Bezerra. São Paulo: 34 Editora, 2001.

MARAVALL, José Antonio. A cultura do Barroco: análise de uma estrutura histórica. Trad. Silvana Garcia. São Paulo: Edusp, 1997.

SARDUY, Severo. Barroco. Trad. Maria de Lurdes Júdice e José Manuel de Vasconcelos. Lisboa: Vega, s/d.

STAIGER, Emil. Conceitos fundamentais da poética. Trad. Celeste Aída Galeão. Rio de Janeiro: Tempo Brasileiro, 1975.

VASCONCELOS, Viviane. O alegórico em Antes do Degelo, de Agustina BessaLuís. In: XI Congresso Internacional da ABRALIC. São Paulo, USP, 2008. Disponível em: http://www.abralic.org/anais/cong2008/AnaisOnline/ simposios/pdf/076/VIVIANE_VASCONCELOS.pdf 